\title{
Conceptos estructurantes de la educación a distancia
}

\author{
Pedro Antonio Vela González ${ }^{1}$ \\ Vicky del Rosario Ahumada de la Rosa ${ }^{2}$ \\ José Humberto Guerrero Rodríguez ${ }^{3}$
}

\begin{abstract}
Resumen
La sociedad del conocimiento impone retos a la educación; la educación a distancia los asume al utilizar las tecnologías de información y comunicación -TIC- que acercan a los individuos no solo para realizar su proceso formativo sino también para hacer parte de una comunidad de conocimiento, ya que se constituye en una estrategia para la inclusión social. En este artículo, se revisan definiciones propias de la educación a distancia, sus antecedentes, el rol que asume el estudiante como gestor de su aprendizaje con el apoyo docente, los tipos de recursos e instituciones educativas y su transformación histórica con base en la implementación de TIC que media entre otras, la interacción profesor-estudiante. Posteriormente, con una visión didáctica, se introduce el ambiente de aprendizaje como el espacio de gestión e interacción social que, apoyado con
\end{abstract}

\footnotetext{
1. Doctor en Educación Nova Southeastern University - EUA, Magister en Educación U. Javeriana, Magister en Educación U. Santo Tomás, Especialista en Educación U. Santo Tomás, Especialista en Evaluación en Entornos Virtuales de Aprendizaje U. de Granada España, Licenciado en Química U. Pedagógica Nacional. Investigador del Grupo Ambientes de Enseñanza Aprendizaje de las Ciencias Básicas (AMECI), Categorizado por Colciencias y Avalado por la Universidad Nacional Abierta y a Distancia (UNAD) y la Universidad Distrital Francisco José de Caldas (UDFJC).

Correo: pedro.vela@unad.edu.co

ORCID: http://orcid.org/0000-0001-6990-9026

2. Doctor en Educación Nova Southeastern University - EUA, Magister en Administración y Supervisión Educativa U Externado de Colombia, Especialista en Pedagogía para el Desarrollo del Aprendizaje Autónomo U. Nacional Abierta y a Distancia (UNAD) y Licenciada en Ciencias de la Educación U. del Atlántico. Docente de la Escuela Ciencias de la Educación en la UNAD. Investigadora del Grupo Ambientes de Enseñanza Aprendizaje de las Ciencias Básicas (AMECI), Categorizado por Colciencias y Avalado por la Universidad Nacional Abierta y a Distancia (UNAD) y la Universidad Distrital Francisco José de Caldas (UDFJC)

Correo: vicky.ahumada@unad.edu.co

ORCID: http://orcid.org/0000-0002-8797-331X

3. Doctor en Educación Nova Southeastern University - EUA, Maestría en Docencia Universitaria U. de la Salle y Químico U. Nacional de Colombia. Investigador del Grupo Ambientes de Enseñanza Aprendizaje de las Ciencias Básicas (AMECI), Categorizado por Colciencias y Avalado por la Universidad Nacional Abierta y a Distancia (UNAD) y la Universidad Distrital Francisco José de Caldas (UDFJC).

Correo: jose.guerrero@unad.edu.co

ORCID: http://orcid.org/0000-0002-8252-6473
} 
la tecnología, exige al docente conocimientos, saberes, habilidades y actitudes diferentes a las tradicionalmente utilizadas, las cuales hacen considerar la educación a distancia más como una modalidad que una metodología, dada la intencionalidad que tiene en el proceso formativo mediado y la necesidad de construir una comunidad de aprendizaje, cuya interacción comunicativa busca la construcción individual y colectiva de conocimiento. Finalmente, se revisan los factores de gestión y la necesidad de establecer políticas para la educación a distancia que promuevan su desarrollo y consoliden su calidad como modalidad educativa.

Palabras clave: Educación a Distancia, Modalidad, Calidad, enseñanza, aprendizaje.

\title{
Structuring Concepts of Distance Education
}

\begin{abstract}
The knowledge society has challenges to education; distance education are assumed using information and communication technologies (New Technologies) that bring individuals not only on their learning process but also to be part of a community of knowledge, as it constitutes a strategy for social inclusion. In this article, we pint out, "own definitions" of distance education, background, assumed the role as manager of the student learning with faculty support, kinds of resources and educational institutions and historical transformation-based implementation is reviewed average among others, teacher-student interaction. Subsequently, an educational vision, the learning environment is introduced as the link management and social interaction, supported by technology, it requires the teaching expertise, knowledge, skills and attitudes other than those traditionally used, which they consider education distance more like a mode that methodology, given the intention that has mediated in the training process and the need to build a learning community whose communicative interaction seeking individual and collective construction of knowledge. Finally, management factors and the need to establish policies for distance education to promote development and strengthen its quality as an educational modality are reviewed.
\end{abstract}

Keywords: Distance education, modalities, quality, teaching, learning. 


\section{Definición de educación a distancia}

La educación libera al hombre de las limitaciones causadas por la ignorancia y la dependencia al ampliar su libertad física y mental, permitiéndole controlar su vida y su entorno (Perraton, 1981).

Lo humano es pensamiento y comunicación. Teoría, cosmovisión e indagar por el saber son actividades mentales exclusivas del ser humano ligadas a su estructura cognitiva. La comunicación educativa tiene un carácter netamente formativo, al buscarse una toma de conciencia a partir de la reflexión y de la discusión, así que cada tipo de educación responde a un marco teórico y a una forma específica de comunicación. Así, lo educativo puede verse desde el objeto y el sujeto implicados en lo educativo: si el objeto es la educación, su énfasis estará en los contenidos y en los efectos esperados, pero si el centro es el sujeto entonces estará en el proceso educativo como tal (Kaplún, 1998).

Este preámbulo es para diferenciar lo educativo desde lo formal, como lo institucionalizado dentro de una sociedad y lo informal que complementa saberes, habilidades y actitudes ganadas en la experiencia. Esta dualidad define la validez de lo educativo y la forma institucional de hacerlo, de cara al reconocimiento social que tiene la experticia de un individuo.

En la declaración de Ciudad del Cabo en 2007, se considera a la educación abierta como una oportunidad de brindar recursos educativos en la internet, disponibles para todos los procesos educativos, como una estrategia para que cualquier individuo pueda acceder a la educación, al desarrollo de una pedagogía cooperativa y colaborativa en la creación e implementación de los mismos donde los profesores puedan compartir experiencias para la elaboración de actividades de aprendizaje. Sin embargo, este esfuerzo es escaso si no se cuenta con políticas del Estado que promuevan este tipo de actividades para hacer mucho más eficaz la educación a nivel global (Open Society Institute, 2007).

En París, durante el año 2012 se realizó un Congreso Mundial sobre los Recursos Educativos Abiertos y basados en el derecho a la educación; le propone a los Estados desarrollar políticas sobre el desarrollo de estos medios para: 1) fomentar su conocimiento y usos, 2) crear entornos adecuados para el uso adecuado de las Tecnologías de Información y la Comunicación (TIC), en la educación, 3) formular políticas y estrategias para el desarrollo de estos recursos, 4) promover el conocimiento y uso de las licencias abiertas, 5) promover el desarrollo sostenible de materiales de aprendizaje de alta calidad, 6) impulsar alianzas estratégicas que promuevan el uso de estos recursos educativos, 7) desarrollar materiales en idiomas y contextos culturales diferentes, 8) promover la investigación en el desarrollo, uso y eficacia de estos recursos, 9) los materiales educativos desarrollados con fondos públicos deben tener licencias de uso abiertas (Unesco, 2012). 
Así, la fundamentación de esta propuesta es la de brindar educación para todos, promoviendo el aprendizaje para toda la vida y utilizar el internet para colocar esos recursos que ayuden a la consolidación de estrategias de aprendizaje. Así, es posible promover el acceso a la educación en todos sus niveles formales y no formales disponibles en el sistema educativo nacional, brindando posibilidades a todas y todos de disponer de medios educativos para aprender durante toda la vida, contribuyendo a la inclusión social, a la igualdad y al acceso de muchas oportunidades para todas las personas con diferentes necesidades educativas (Ángeles, 2013).

Desde esta perspectiva, en este documento se propone tomar la definición de educación a distancia propuesta por Simonson, Smaldino, Albright y Zvacek (2009: 32), "es una educación formal orientada por una institución en la que el grupo de estudiantes se encuentran distantes y mediante un sistema de comunicación interactivo, se relacionan estudiantes, profesores y recursos educativos".

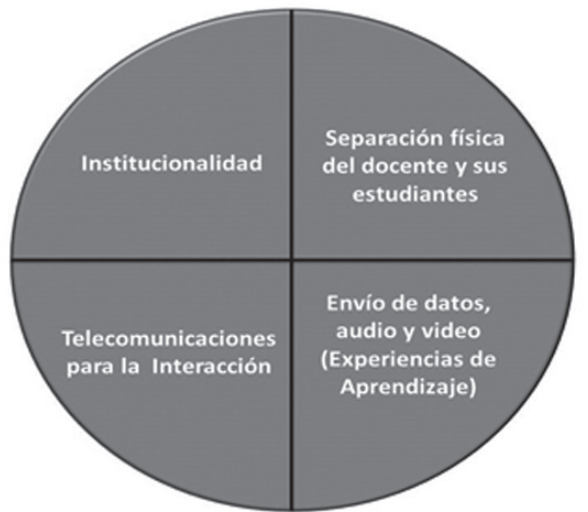

Figura 1. Elementos claves en la definición de la educación a distancia. Tomado de Simonson, et al. (2009, p. 32)

En la definición, hay cuatro componentes para un sistema educativo a distancia, como se muestra en la Figura 1. Uno es la institucionalidad de la formación educativa que la diferencia del autoestudio y se relaciona con sujeción a la ley y a la normatividad de la organización educativa basada en su autonomía. El segundo es la separación física del docente y el grupo de estudiantes, que viene siendo una de las características más específicas de la educación a distancia. Sin embargo también se debe considerar la separación física entre los mismos estudiantes, indicando espacios de independencia intelectual, de disponibilidad de recursos y de tiempos diferentes para la comunicación. El tercero es la comunicación mediada o telecomunicación interactiva, siendo un elemento crítico en la experiencia de aprender a distancia ya que al tener ubicación geográfica distinta, las interacciones mediadas entre recursos educativos, docentes y condiscípulos facilitan o entorpecen la vinculación al proceso educativo social que se da en el aula tradicional o virtual. El último componente se relaciona con las experiencias de aprendizaje que se den en la comunidad académica a distancia siendo el centro del proceso formativo (Schlosser y Simonson, 2010). 
Si la educación a distancia se basa en recursos educativos y en la disponibilidad de los mismos en la web, entonces es un medio eficaz para promover todas las oportunidades educativas desde los niveles iniciales hasta los más avanzados de un sistema educativo. Esto porque actualmente el acceso a la información es fácil y masivo, replanteando nuevos roles para la institución educativa, los docentes y los mismos estudiantes; el conocimiento tiene un nuevo valor social y económico, la interconectividad, la flexibilidad sostenible y el teletrabajo entre otras (Marcelo, 2001).

El centro del aprendizaje es el estudiante, quien modifica sus esquemas cognitivos para atender a necesidades específicas. Esa necesidad le establece estrategias cognitivas y metacognitivas para seleccionar instituciones, recursos e interacciones para lograrlas, por lo que el sistema educativo debe prepararlo para asumir ese reto. Así debe involucrarse en una comunidad de indagación que mediante el trabajo individual y colaborativo pueda adquirir los conocimientos, habilidades y actitudes que le permitan satisfacer esas necesidades productivas que lo han llevado a educarse. Es esencial que la educación formal y no formal propendan por enseñar a aprender, es decir, por enseñarle herramientas para la búsqueda de información, el estudio y la consolidación de la información dentro de un grupo o comunidad de aprendizaje que es la misma institución educativa. El papel de la institución educativa es definir los contenidos de trabajo para el desarrollo de las competencias esperadas, los lenguajes de expresión del acto mental, la realización del acto mental de aprender (insumo, proceso y producto), las operaciones mentales requeridas en ese acto mental, el nivel de complejidad adecuado al nivel educativo; si es educación superior, necesariamente serán las actividades mentales superiores, nivel de abstracción deseado y nivel de eficacia (Anónimo, s.f.; Wompner \& Fernández, 2007).

El mundo cada vez más se está volviendo global y local. En lo primero, la interconectividad, la innovación, el incremento en el uso de la tecnología, la influencia de los contextos sociales, culturales, políticos y económicos de diferentes grupos de naciones, y las interfaces de conectividad de la conectividad y la comunicación entre individuos y naciones, hacen que en lo educativo se desarrollen acciones para lo atemporal de la formación que se asume desde una fuerte formación en ciencias básicas como adaptación a los constantes cambios en la tecnología, facilitando lo adaptativo de los escenarios laborales y lo educativo para afrontarlos exitosamente, al desarrollo de lo analítico como capacidad para afrontar la creatividad, la productividad y el liderazgo necesario para asumir esos cambios. A ello se une el autoconocimiento como medio de conciencia para saber de sus debilidades y fortalezas para transformarlas en oportunidades que marquen una actuación competente y, finalmente, el autocontrol para lograr el equilibrio personal en el pensar, actuar y sentir (Capacho, 2011).

La educación a distancia es una modalidad educativa que hace parte del sistema educativo para brindar más oportunidades de formación a los ciudadanos acorde 
a sus necesidades, para que participen de los beneficios sociales del conocimiento para lograr el bienestar.

\section{Antecedentes de la educación a distancia}

La educación a distancia se presenta como una de las tantas estrategias formativas que pueden resolver muchos de los problemas educativos que van desde el aislamiento geográfico de los estudiantes de los centros del saber hasta la necesidad de perfeccionamiento constante que está introduciendo la sociedad del conocimiento, sin olvidar el ahorro de dinero y del tiempo que supone, o la magia del mundo interactivo en que nos introduce (Cabero, 2006).

Para comprenderla mejor, Barberá (2008), plantea algunos antecedentes desde dos perspectivas: la primera corresponde a un enfoque global y hace referencia a la progresión histórica de la educación a distancia, que, de la mano con la tecnología, ha desembocado en el e-learning. La segunda, es más focal y se refiere a las etapas que ha seguido internet en su corta historia en el ámbito de la educación a distancia.

Para ofrecer una visión amplia del avance a través del tiempo de la educación por correspondencia al e-learning, se siguen parámetros estrictamente cronológicos. Se presentan entonces, cinco generaciones de la tecnología de la educación a distancia que se describen a continuación:

Primera generación. Los estudios por correspondencia, fueron el primer tipo de educación a distancia implementado en el que se utilizó el sistema postal. En este sentido, Garrison y Anderson (2011), afirman que esta generación se caracterizó por los rasgos tópicos de un modelo industrial, en el que se aplica la economía de escala mediante una división Taylorista del trabajo. Este modelo de producción en masa permitía que los sistemas de educación a distancia crearan cursos y programas de alta calidad y que pudieran llegar a buen precio a miles de estudiantes. Conforme a los puntos de vista de la teoría industrializada de Peters (Simonson, Smaldino \& Albright, 2009), se considera a la educación a distancia como una modalidad educativa adecuada a las necesidades educativas de la sociedad postindustrial y como un sistema de formación masificado, basado en la industrialización de la educación.

Segunda generación. La audiodifusión, determinada por la invención de la radio y sistemas de radiodifusión, surge como alternativa para el complemento de los estudios por correspondencia utilizando la radio, televisión, satélites y video (Simonson, et al., 2009). Es así como Garrison et al. (2011), plantean que esta generación surge en el marco de una época definida por las nuevas tecnologías de masas y una aceptación creciente de la teoría cognitiva, creando productos mediáticos (telerecursos) de gran envergadura y a menudo muy costosos que 
permitieron a los estudiantes visitar virtualmente el laboratorio, el lugar de trabajo, o permanecer en clase con la información entregada por sus docentes. Con esto se pretendía mantener su atención en el estudio independiente a partir de la teoría de independencia de Wedemeyer (Simonson et al., 2009. p. 42), en la que se plantea que la esencia de la educación a distancia era la independencia del estudiante, ya que presentaba pocas restricciones de tiempo y lugar para el estudio con los telerecursos.

Tercera generación. Kaufman (1989), basa esta generación en medios de comunicación bidireccional, permitiendo así una interacción directa entre el docente y el estudiante, y a menudo entre los mismos estudiantes distantes, de forma individual o en grupos. Esta generación explota las ventajas que ofrece la posibilidad de interacción humana tanto sincrónica como asincrónica, facilitada por toda una serie de tecnologías web 2.0 Así mismo, el sistema de educación a distancia de tercera generación incorpora las teorías constructivistas sobre el aprendizaje. Estas promueven la generación de oportunidades para que los estudiantes creen y re-creen el conocimiento tanto en condición de individuos como en la de miembros de un grupo de estudio (Garrison et al., 2011).

Cuarta generación. En esta generación se combinan los tres grandes atributos de la red: la extracción de grandes volúmenes de contenidos, la capacidad interactiva de la Comunicación Mediada por Ordenador (CMC) y el poder de procesamiento distribuido localmente a través de la programación asistida por ordenador generalmente en Java. El medio para la comunicación es la teleconferencias y se caracteriza por tener formas reales de tecnología de comunicación en línea, entre ellas la audioconferencia, la videoconferencia, el satélite y sistemas de fibra óptica (Garrison, et al., 2011).

Quinta generación. Taylor (como se citó en García, 2002), la describe como un modelo de aprendizaje inteligente y flexible. Añade además a esta generación funciones inteligentes claves como la integración y acceso mediante portales a recursos y servicios del campus virtual. Garrison et al. (2011), afirma que la estamos viviendo hoy en día con la internet y la word wide web (www) y se espera con ella un rápido desarrollo de las innovaciones pedagógicas. La quinta generación para Berners-Lee, Hendler y Lasila, (2001), incorpora inteligencia artificial en la Web, lo que construye su carga semántica de modo que agentes autónomos tanto humanos como no humanos puedan procesarla y navegar por ella.

Siguiendo las prospectivas indicadas por Barberá (2008), los materiales escritos en papel se traducen a un formato electrónico; mas tarde este material se ubica en red, en el marco de una Web incorporando otro tipo de software (e.g. presentaciones, ilustraciones, audio, video), pero continúa siendo un material para leer y consultar. Después se emiten los primeros cursos en línea que incorporan una tecnología más comunicativa, que más adelante se materializa 
en plataformas educativas integradas de multiusuario como campus virtuales con finalidades de enseñanza masiva y por último, se personalizan los servicios educativos ofrecidos por dichas plataformas. Ahora, para poder precisar que es hoy el e-learning, el Plan de Acción de la Comisión Europea, lo define como el uso de nuevas tecnologías educativas multimedia e internet para mejorar la calidad del aprendizaje facilitando el acceso a los recursos y servicios, así como a los intercambios y la colaboración a distancia (CEPAL, 2001).

Profundizando los componentes del e-learning, Benítez (2010), toma de referente los planteamientos presentados por la Association for Educational Communication and Technology (AECT) y con algunos de ellos, define la tecnología educativa como el estudio y la práctica ética de facilitar el aprendizaje y mejorar el rendimiento mediante la creación, uso y manejo adecuado de procesos tecnológicos y recursos. Garrison et al. (2011), adoptan un enfoque más amplio y se centran en las herramientas en lugar de las técnicas, optando por una definición más exclusiva, y denominan las tecnologías educativas como aquellas herramientas empleadas en la práctica docente formal con el objetivo de difundir, ilustrar, comunicar o introducir a estudiantes y e-tutores en actividades expresamente diseñadas para inducir al aprendizaje. Así mismo, autores como Moore y Kearsley (1996), conciben la educación a distancia, y con ella el e-learning como un sistema complejo integrado por elementos de carácter institucional, individual, técnico y social, lo que predispone a considerar el impacto de un cambio determinado en cada una de las piezas que componen el sistema ya que describe la experiencia del e-learning como un todo integrado y hace que se fije la mirada en todos los componentes interrelacionados cuando se produce un cambio en algún subsistema del sistema total.

\section{De metodología a modalidad en la educación a distancia}

Un ambiente de aprendizaje es un sitio, real o ciberespacial, donde los estudiantes y sus docentes confluyen para interactuar psicopedagógicamente con ciertos contenidos mediados por técnicas y procedimientos para adquirir nuevos conocimientos, desarrollar nuevas habilidades y actitudes que los harán cada vez más competentes (Herrera, 2005).

La incorporación de las TIC en educación hace que el acto educativo de enseñanza y aprendizaje sea estructurado en otras formas para aprovechar las ventajas comunicacionales del medio. Esta concepción es válida para modelos formales más tradicionales de la educación donde estos recursos se constituyen en medios de apoyo a la docencia. Sin embargo, la incorporación tecnológica requiere de procesos de aprendizaje para su uso eficaz; conocer sus ventajas, el tipo de lenguaje que requiere, la forma de entrega de información y las actitudes requeridas para reflexionar sobre los contenidos presentados para su asimilación y discusión en las comunidades de aprendizaje, garantiza su éxito. Cada vez son 
más reconocidas las estrategias de aprendizaje independiente y a distancia como un medio de aprender, donde las mediaciones son las que permiten empoderar la comunicación para la formación. Acá, la innovación es el requisito esencial para lograr la efectividad. Esto porque cada uno de los medios reclama del docente habilidades para tratar, manejar y almacenar la información que quiere impartir. Con esto, es posible fomentar la interactividad, la autonomía, la toma de decisiones, la participación colectiva en la construcción del conocimiento (Fandos, 2006).

Además, las TIC amplían la concepción y la metodología del proceso de enseñanza-aprendizaje al crear nuevos entornos de trabajo, comunicación y aprendizaje basados en una plataforma, recursos educativos y herramientas interactivas, todos ellos ubicados en la Web siendo muy flexibles y de relativo acceso. Estas condiciones hacen ver a la educación a distancia más una modalidad educativa que una metodología. Lo anterior a la necesidad de reconceptualizar el acto pedagógico como tal (el aula, los recursos didácticos, la identidad y roles del docente,...), la estructuración de los contenidos, el uso de recursos abiertos, el grado de interactividad que tenga tanto el docente como el estudiante, y el cambio de la práctica docente en la enseñanza y en el aprendizaje centrado más en el estudiante. Esto comprende combinar concepciones pedagógicas, tecnologías, relación de actividades con entorno práctico y metodologías de enseñanza tradicionales y mediadas, estrategias de apoyo académico y el uso de algún diseño instruccional (Turpo, 2012).

Si lo típico de la educación a distancia es la separación física y la comunicación medida, esta no es una condición específica en su modelo pedagógico ya que precisamente se elimina esa barrera al generar condiciones en el acto pedagógico que se ajusten a las necesidades del estudiante, a que disponga de los recursos educativos adecuados que le reduzcan sus limitaciones de tiempo, espacio, cognitivas y otras que le disminuyan sus posibilidades de lograr ser un individuo integral, partícipe de una sociedad. Es precisamente en ese modelo desde donde se establece un modo sistémico para impartir la enseñanza generando la autonomía en el estudiante para que aprenda, teniendo en cuenta que hay condiciones como la holoconectividad o conexión libre del tiempo, la ubicuidad por la posibilidad de conectarse desde cualquier lugar, la metadimensionalidad por la interacción comunicacional de diferentes medios, la comunicación sincrónica y asincrónica, el espacio virtual en red y el aula virtual como punto de encuentro comunicacional pedagógica (Arancibia y Pérez, 2002).

Lo anterior justifica la consideración de la educación a distancia como una modalidad porque es una forma de realizar formación de personas que tienen necesidades específicas, requiriendo adecuaciones curriculares para que puedan alcanzar los logros establecidos en el sistema educativo, permitiéndole su vinculación a otras formas educativas y con ello su mejor desarrollo humano, sin ninguna discriminación (Serrano y Muñoz, 2008; Díaz, 2011). 
Finalmente, es posible establecer como características específicas de la modalidad de educación a distancia la autonomía y autocontrol del aprendizaje que realiza el estudiante, como centro del acto educativo, la diferencia en interactividades que se gestionan en el aula de manera sincrónica y asincrónica, la autenticidad de la realidad que se aprende al disponer de múltiples medios que pueden mostrar sus múltiples propiedades, la apertura en lo educativo quedando en la decisión del estudiante la selección de medios, recursos y estrategias para consolidar las competencias que desea alcanzar, el aprendizaje colaborativo al estructurarse en una comunidad de indagación y de intercambio de saberes con propósitos comunes como es la construcción de un conocimiento socialmente aceptado, el monitoreo que puede realizar el docente y la comunidad de aprendizaje, la evaluación informatizada donde el estudiante tiene múltiples oportunidades para demostrar su desempeño y la relativa facilidad de uso de plataforma, recursos e interactividades (Capacho, 2011).

\section{Enseñanza y aprendizaje en la educación a distancia}

El mundo pide acción. En educación los paradigmas se mueven hacia el estudiante considerándolo el centro del proceso de enseñanza y de aprendizaje. El aprendizaje activo tiene como ventajas: el que involucra más al estudiante al permitirle empoderar su capacidad de decisión, le motiva a aprender a aprender al desarrollar sus estrategias metacognitivas, tiene especial importancia para los profesores pues se desempeña como asesor y guía lateral, desarrolla habilidades para afrontar el mercado laboral al tener capacidades para la solución de problemas, permite vincular la educación con el mundo laboral fomentando la educación para toda la vida (Capacho, 2011). En otras palabras, se necesita un aprendiz autónomo, autorregulado, proactivo y competente.

Lo anterior, establece la necesidad de reconsiderar el significado de enseñar y de aprender, como también su vinculación con el acto educativo comunicacional donde interactúan estudiantes y profesores teniendo un objetivo común como es la construcción de una comunidad de indagación (Garrison y Anderson, 2005). En este sentido, enseñar es un proceso de ayuda para que alguien pueda construir, mediante el intercambio en un contexto pedagógico saberes, habilidades y actitudes. Requiere de un iniciador que es el enseñante, un profesor que domina un conocimiento, sabe cómo se aprende, establece estrategias para lograrlo, valora los resultados y reflexiona para mejorarlo. Estas actividades son insumos para la planificación creativa e innovadora de estrategias de enseñanza. El aprendizaje, entonces, supera la acumulación de información o el ejercicio repetido de habilidades para facilitar la construcción participativa de representaciones personales tanto individual como en grupo dando significados, practicando y generando identidad dentro de una comunidad de investigación formativa (Díaz y Hernández, 2010). 
Por lo tanto, para la educación a distancia, el acto educativo requiere de un proceso de planeación de la enseñanza y de la construcción de estrategias para implementarla ya que es una de sus etapas. En ésta, la mediación juega un factor comunicacional importante ya que debe guiar al estudiante en su tarea de aprender, en las orientaciones para combinar teoría y práctica cuando esté trabajando con los recursos de aprendizaje recomendados o que él libremente seleccione para modificar sus esquemas cognitivos acorde a los propósitos de aprendizaje previamente pactados (Martín, Verde y Yelicich, 2011). El aprendizaje en educación a distancia corresponde a la actividad individual y en grupo que realiza el estudiante dentro de su comunidad de aprendizaje que tiene como punto de encuentro el aula presencial o virtual, dependiendo de la generación de educación a distancia que se encuentre la institución que oferta programas a distancia (Ramos y Arias, 2012; Garrison, et. al., 2005).

Según Aliste (2006), establece que la educación a distancia caracterizada por la comunicación bidireccional estudiante-docente, la mediación comunicacional mediante tecnología y la separación de estudiantes y profesores hacen posible múltiples formas o modos de realizar el acto educativo, permitiendo identificar el Flexible Learning donde cada estudiante atiende su necesidad formativa utilizando todas las herramientas y recursos disponibles, el Distributed Learning que distribuye recursos mediante redes de comunicación conformados por nodos y usuarios que intercambian, el Distance Learning donde el tutor es el organizador y el controlador del proceso formativo quedando en responsabilidad del estudiante su desarrollo, el Open Learning, un proceso educativo independiente del tiempo y que gestiona el estudiante a su propio ritmo y el $e$-Learning donde el acto pedagógico se soporta mediante internet y todos sus recursos aprovechando su característica multimedia.

Finalmente Area (2002), establece como ventajas pedagógicas de la incorporación de internet la ampliación de usuarios del sistema educativo, el profesor no es la única fuente de información, la interactividad permite profundizar más en el saber al ubicarlo, comprenderlo, asimilarlo y transformarlo de manera individual y colectiva, la red incrementa la autonomía y las tomas de decisión por parte del estudiante, se da flexibilidad de tiempo y lugar para el desarrollo de lo educativo en el aula de clase, la red cambia los modos, formas y estrategias de interacción de estudiantes y profesores en la comunidad de aprendizaje, promueve la colaboración de estudiantes y profesores en la construcción de saberes, procedimientos y actitudes. Esto implica cambiar la pedagogía para sacar el mejor provecho de la tecnología. En otras palabras, es generar procesos de innovación que da más cuenta de una modalidad educativa que una metodología.

Herrera (2005), presenta un modelo didáctico para ejecutar el proceso de enseñanza-aprendizaje diferenciando tres etapas, la de prescripción que enfatiza en la planeación del proceso, la de instrumentalización donde se construyen, 
seleccionan y articulan las estrategias de enseñanza y la última de operación y evaluación que tiene que ver con el aprendizaje.

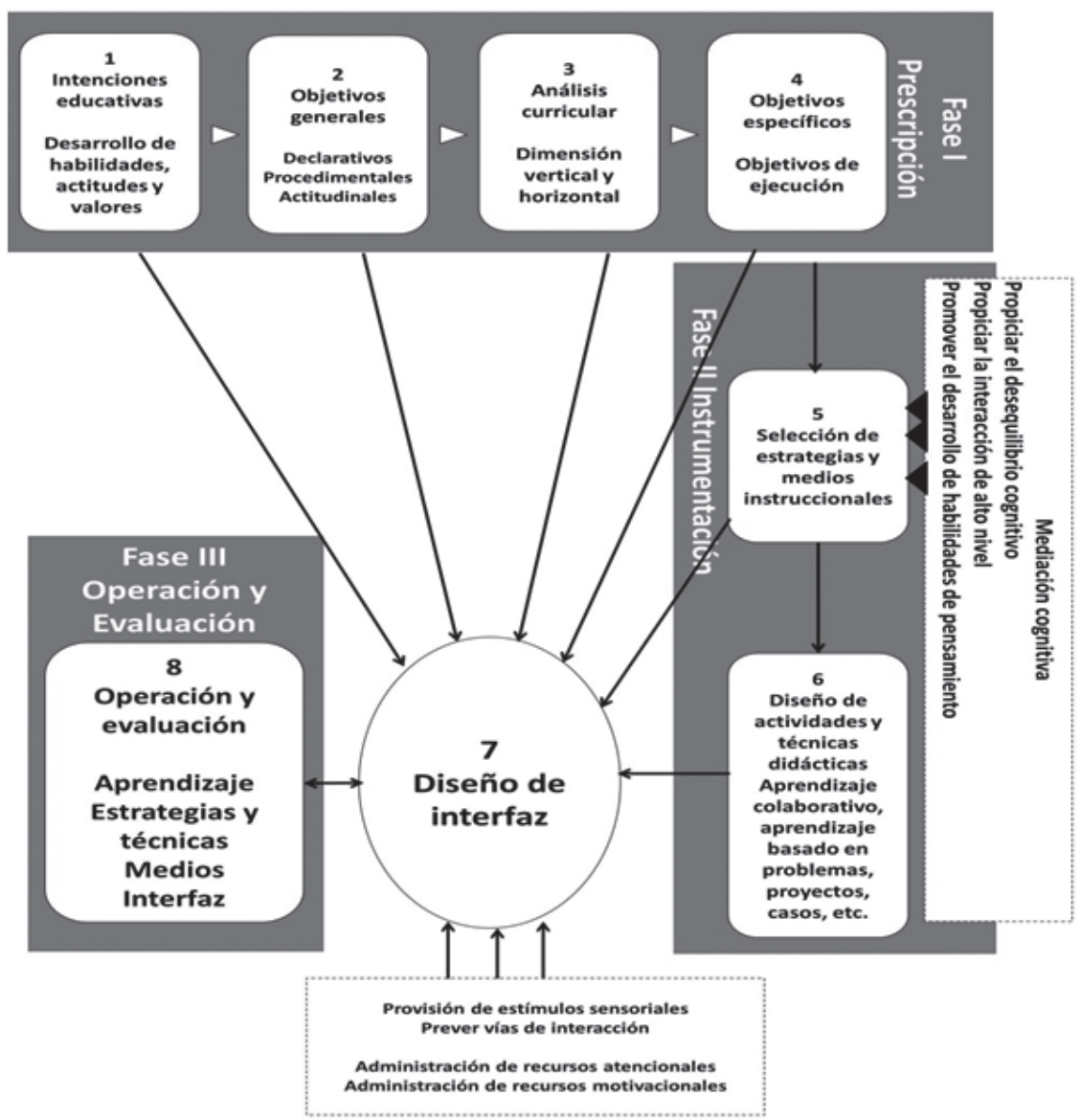

Figura 2. Modelo para la enseñanza y el aprendizaje en educación a distancia. Tomado de Herrera (2005, p. 12)

La primera fase, estrictamente de planeación académica, tiene cuatro etapas; en la primera se determinan cuáles son las intencionalidades formativas conforme a la teleología de la educación y la institución que oferta el curso dentro de un programa académico de formación, en la segunda se determinan los objetivos o intencionalidades formativas expresados en contenidos cognitivos, metodológicos y de actitudes que harán competente a la persona que asuma un compromiso formativo acorde a sus intereses y necesidades, en la tercera se define un currículo y una estructura curricular de va de lo simple a lo complejo conforme el estudiante avanza en el programa de formación y finaliza con el 
planteamiento de objetivos o propósitos específicos que determinan el espacio académico del curso donde el estudiante tendrá la oportunidad de demostrar su desempeño.

La segunda fase o de instrumentalización dispone de un referente dado desde lo cognitivo y que está en estrecha relación con las concepciones de aprendizaje y de enseñanza que tenga la institución expresadas en su proyecto curricular y pedagógico y en la intencionalidades formativas que van a caracterizar al futuro egresado de cara a un entorno cambiante y retador. Acá se pone en juego lo pedagógico y lo didáctico que tiene la mediación de los contenidos propuestos en el currículo y que entran en negociación con el estudiante. Tiene dos pasos, uno relacionado con las estrategias de enseñanza, el sistema de mediaciones a utilizar dependiendo de los recursos institucionales identificados en cada una de las generaciones por las que deviene la educación a distancia y la segunda, con la definición de las actividades de aprendizaje y de evaluación que va a tener el curso alineadas estrechamente con los propósitos u objetivos de formación y los contenidos programados. Esta prospectiva será uno de los factores de calidad para medir la eficacia del sistema de educación a distancia propuesto.

Finalmente, la fase tres o de operación y evaluación, tiene que ver con el proceso de aprendizaje en sí que está centrado en el estudiante. Mediante un sistema de interacciones comunicativas con fines educativos, seguirá el derrotero propuesto asistido por las mediaciones definidas por los recursos educativos puestos a su disposición y a la toma de decisiones que haga en la ubicación de otros que le ayudan a complementar sus necesidades de aprendizaje. La idea es que en esta fase vaya desarrollando habilidades metacognitivas que le permitan ser un aprendiz autónomo, crítico, innovador y competente de cara al aprender a aprender para toda la vida como lo requiere el mundo de hoy (Capacho, 2011).

Por otra parte, la séptima etapa aparece como el puente entre lo que se consideraría la enseñanza y el aprendizaje en educación a distancia acá propuesto. La interfaz corresponde a la estructuración de currículo, curso, estrategias mediadas de enseñanza y de actividades de aprendizaje y evaluación y que entregará en impresos, recursos audiovisuales o en plataformas virtuales que haya definido la institución para la entrega de su docencia a las poblaciones que se van a beneficiar del servicio educativo ofertado. Al ser el punto de inicio, debe generar motivación y compromiso del futuro estudiante.

El modelo pedagógico y didáctico anterior, enfatiza lo comunicacional que caracteriza el acto educativo. La interacción que se da entre estudiante, profesor, contenido e institución es un referente importante para que cualquier propuesta educativa basada en la modalidad de educación a distancia sea efectiva y eficaz en la formación de personas que desean contribuir al desarrollo de su sociedad como parte de un proyecto de vida. 


\section{La comunicación pedagógica y didáctica en la educación a distancia}

Se puede afirmar que en cada modalidad educativa, existe una determinada concepción y una práctica de comunicación. Eso significa que dependiendo de las concepciones que la institución de educación a distancia tenga sobre cómo orientar el proyecto de formación que oferta, así será el tipo de comunicación que imparte.

Si sigue un modelo tradicional centrado en el profesor y el texto, es posible que lo esencial en el acto comunicativo sea la transmisión de información para su posterior reproducción por parte del estudiante; la coincidencia que se tenga en la reproducción de los mensajes educativos, así será de exitoso el estudiante. Acá no hay espacio para el diálogo, confrontar ideas y compartir el concepto; el profesor sabe, el alumno debe aprender. Pero si se busca un cambio, la comunicación es persuasiva, es decir, se convence al otro para que asuma un comportamiento esperado sin que tenga que reflexionar sobre su conveniencia o no; es muy útil para el entrenamiento, donde el alumno sigue instrucciones muy claras y convincentes constituyéndose en la mejor información de retorno de sus actitudes ante la formación. Sin embargo, en la búsqueda de modelos educativos centrados en el aprendiz, en el estudiante, la comunicación debe centrarse en el individuo y en su proceso de aprendizaje, es decir, será transformadora que promueve acción-reflexión-acción para construir una realidad desde su experiencia y su práctica social, empoderando un individuo crítico y autónomo, capaz de aprender a aprender y a solucionar problemas y conflictos. Se caracteriza por ser dialógica y promover la participación (Kaplún, 1998).

Este marco permite considerar que la comunicación en educación a distancia es mediada, pero con los avances en las TIC, se ha tornado más multidimensional, menos lineal y con más imagen, sonido y movimiento. Además se tienen herramientas de comunicación sincrónicas (web-conference y chat) y asincrónicas (correo electrónico, foros), sin embargo si se requieren otras condiciones como las características de los receptores, el sistema simbólico acorde a los participantes, la forma de presentar el mensaje y las diferentes redes de comunicación. Esto implica afectar lo cognitivo-afectivo, lo significativo, y la sencillez para favorecer su comprensión y asimilación. Esto porque la comunicación educativa debe informar más que transmitir información, por ello el docente debe ser facilitador, guía y creador de estrategias para la búsqueda, selección, compilación y transformación de la información. La comunicación educativa también es reguladora, es decir, organiza, promueve y consolida las interacciones individuales y colectivas dentro de un curso. Finalmente la comunicación es afectiva al promover el respeto y la consideración al que escribe aportando en la construcción del saber dentro del aula (Rojas, 2003). 
En esa forma, la comunicación educativa considera un interlocutor discursivo que da sentido a los mensajes, a la mediación, a la intersubjetividad. Es a través del lenguaje, enriquecido con el entorno social, cultural, ético, de género entre otros que se construye un significado que se comparte en el diálogo social mediado (palabras, signos, metáforas, imágenes y sonidos) que en el juego de una negociación, se llegan a acuerdos sobre el conocimiento consolidando una comunidad de indagación, una comunidad de aprendizaje (Citelli, 2011).

En ese sentido, Anderson y Kuskis (2007), han construido un modelo de interacciones para la educación a distancia considerando tres componentes fundamentales que intervienen en el acto educativo: La institución, los profesores, los estudiantes y los contenidos. Estos autores describen seis interacciones que se evidencian en la Figura 3.

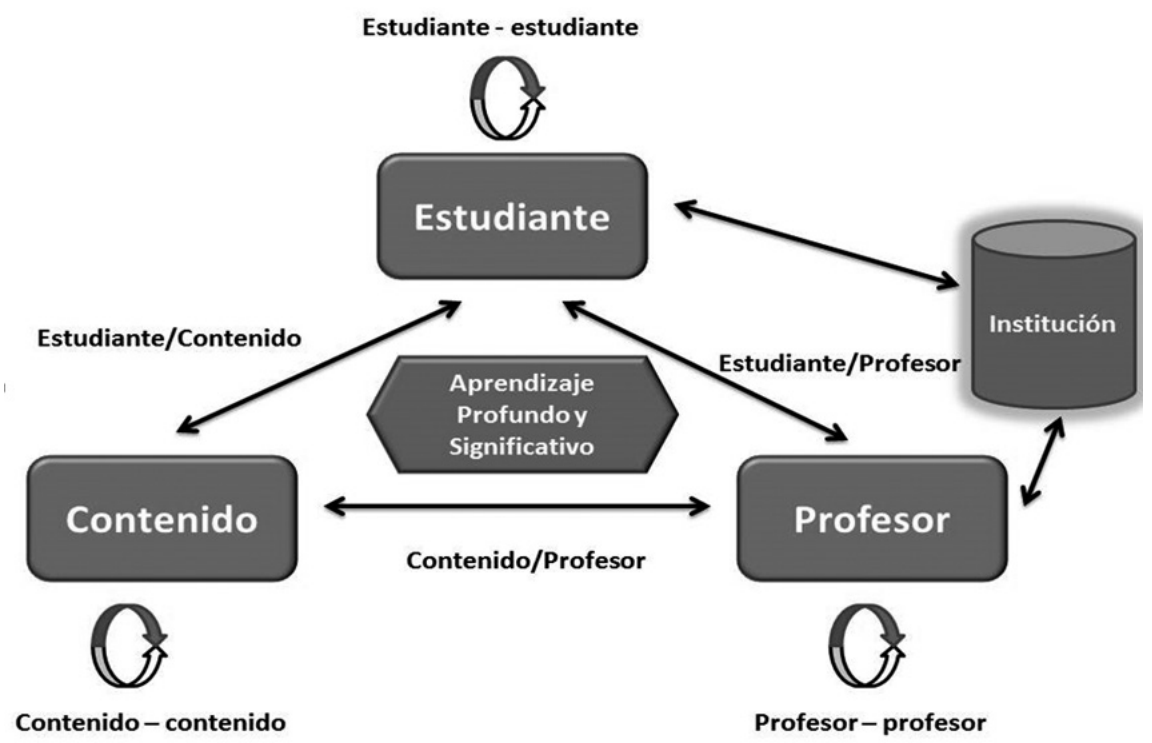

Figura 3. Interacciones en el acto educativo de la educación a distancia. Tomado de Anderson y Kuskis (2007, p. 297).

Cada una de esas interacciones tiene unos componentes comunicativos que determinan las estrategias pedagógicas y didácticas que orientan el ejercicio académico del estudiante dentro del curso. Es de anotar que estas interacciones no se dan únicas sino que participan en el desarrollo del proceso de aprendizaje que adelanta el estudiante.

Interacción estudiante-estudiante. Favorece el aprendizaje colaborativo y cooperativo, permitiendo niveles de motivación eficaces, el libre intercambio de ideas y la información de retorno oportuna entre los participantes. Así, es posible generar un aprendizaje profundo, aunque es necesario acompañarlos durante el 
proceso argumentativo y propositivo, posibilitados mediante comunidades de indagación y de aprendizaje. Sin embargo, ese trabajo debe estar contextualizado y realizarse mediante la dinamización de redes de comunicación mediadas. El aprendizaje colaborativo supone: 1) el aprendizaje es un proceso creativo activo, 2) requiere de un contexto muy enriquecido, 3) es social, 4) es afectivo y subjetivo, 5) se desarrollan saberes y habilidades. Sin embargo, esas condiciones deben ser enseñadas, apoyadas técnica y académicamente por la institución y los profesores al estar afectadas por el tiempo de dedicación que tenga el estudiante (Anderson, et al., 2007).

Para estos autores, el trabajo con los pares es otro elemento fundamental en el proceso de aprender. Esto porque no solamente es la esencia de la comunidad de aprendizaje sino que es una habilidad de desempeño profesional. Es importante aprender métodos, lenguajes y la cultura para hacer parte de la comunidad de aprendizaje. Para la educación a distancia es esencial el desarrollo de esta interactividad por razones sociales que ayudan a cohesionar los grupos de aprendizaje y el intercambio de información para la construcción del conocimiento reduciendo la deserción. Es posible que al inicio se requiera más apoyo mediante comunicación sincrónica, motivación para la incorporación y consolidación de la comunidad de aprendizaje y orientaciones para comunicaciones en línea exitosas. Sin embargo, el diseño instruccional debe considerar esas interacciones favoreciendo el aprendizaje individual y social en respuesta a las necesidades de cada aprendiz.

Interacción aprendiz-contenido. Corresponde al proceso que más tiempo le consume al estudiante al tener que trabajar textos, guías de aprendizaje y otros recursos educativos, los cuales se pueden clasificar en categorías como sonidos, textos, imágenes, video y realidad virtual. Es la más importante porque favorece el logro de los propósitos de aprendizaje, la satisfacción con el proceso de aprender y la realización oportuna de las tareas de aprendizaje y de evaluación. Internet es un medio de almacenamiento de múltiples recursos que se pueden acceder para aprender, comentar o complementar saberes, recibir mensajes de alerta según intereses y de videojuegos (Anderson et al., 2007).

Interacción profesor-contenido. La selección, desarrollo y utilización de objetos de aprendizaje es una de las ocupaciones importantes del profesor de educación a distancia. Internet es una oportunidad para la creación de objetos de aprendizaje que se vinculan al proceso de aprendizaje que deben realizar los estudiantes. En este caso es importante el proceso de diseño instruccional, aunque el postcast y el videocast son formas rápidas de digitalizar eventos presenciales con fines educativos que son posteriormente puestos a disposición de los estudiantes. La ventaja es la relativa facilidad con que pueden ser remplazados o mejorados buscando una utilización cada vez más amigable y desarrollando habilidades de pensamiento superior (Anderson, et al., 2007). 
Interacción profesor-profesor. Es un medio para el trabajo interactivo para el desarrollo pedagógico y de la especialidad en contenidos que maneja el docente. Esta interacción desarrolla el claustro invisible y amplía el colegaje favoreciendo el desarrollo de habilidades en el área de conocimiento y en el manejo pedagógico y didáctico de los contenidos (Anderson, et al., 2007).

Interacción contenido-contenido. Mediante el uso de buscadores inteligentes es posible recuperar información, generar alertas sobre nuevos contenidos en un área específica, conectar reservorios y bases de datos, además de almacenar recursos. Estas interacciones están en proceso de investigación ya que dependen de factores como la frecuencia, tipos de aprendices, contenidos, propósitos de aprendizaje y la satisfacción del estudiante. Sin contar otros como el costo y el tiempo (Anderson et al. 2007).

Garrison y Anderson (2005), investigando el fenómeno comunicacional en el aula a distancia encontraron que es posible construir una comunidad de indagación o de investigación formativa alrededor de los contenidos que se están enseñando. El concepto clave en su modelo es la presencia la cual se da en tres formas: presencia social, cognitiva y docente. La Figura 4 muestra el modelo y las relaciones que se establecen para consolidar la comunidad de aprendizaje o de indagación.

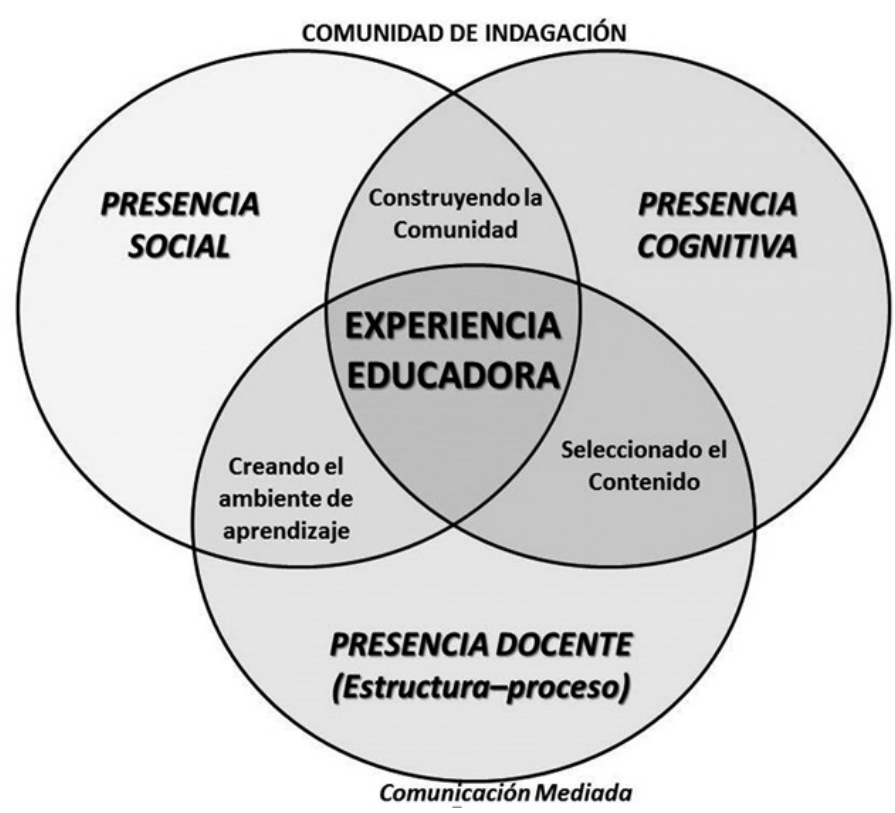

Figura 3. Modelo de una comunidad de indagación o de aprendizaje. Tomado de Garrison et al. (2005, p. 49). 
Según estos autores, la presencia social corresponde a la capacidad que tiene cada miembro de proyectarse como personas emocionales y sociales en el espacio virtual del aula. La presencia docente corresponde al rol del profesor de diseñador, guía, asesor de las actividades de aprendizaje y evaluación que se desarrollarán en el contexto pedagógico del aula, el profesor no desaparece ya que durante el proceso de aprendizaje da apoyo al trabajo académico individual y el del grupo de aprendizaje. La presencia cognitiva se refiere al entorno intelectual que muestra la comunidad de indagación en la medida que progresa en la construcción social del conocimiento mediante el aporte, el debate y la consolidación final de productos de aprendizaje. La Tabla 1, resume más las características de estas tres presencias en el modelo discutido.

Tabla 1. Categorías e indicadores de los elementos de la comunidad de indagación.

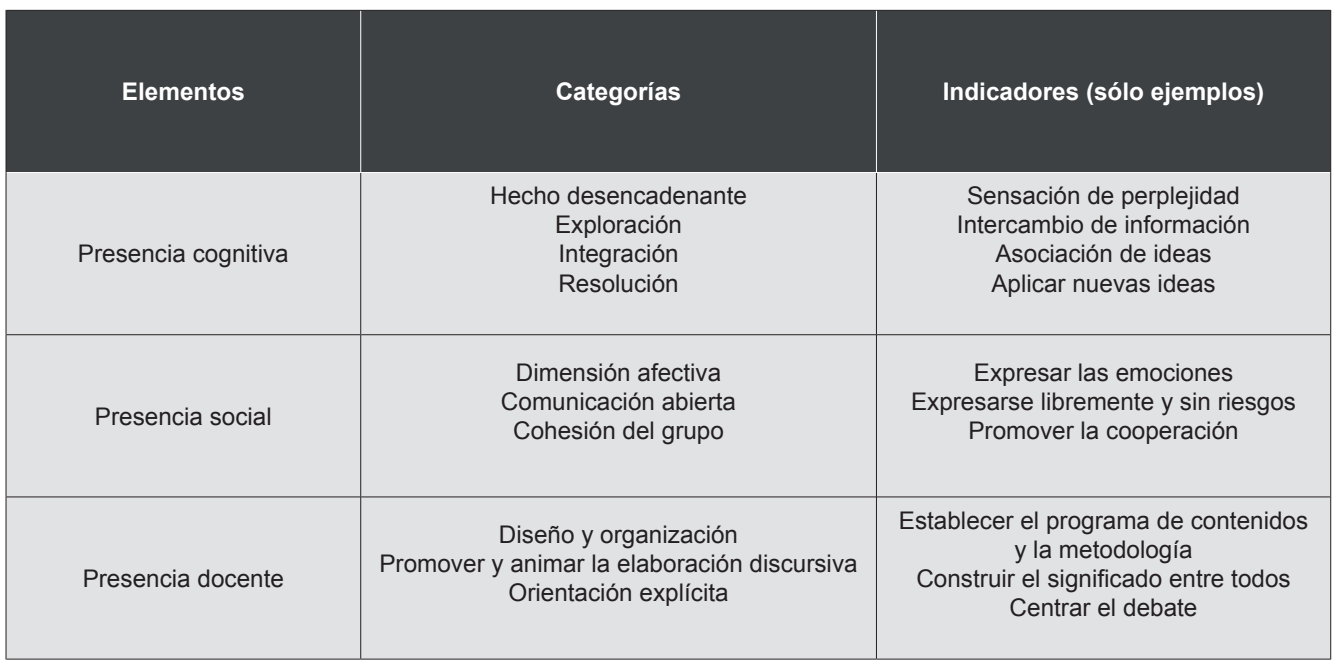

Tomado de Garrison et al. (2005, p. 52).

Así, se comprende que al ser la comunicación un elemento fundamental en el acto educativo de la educación a distancia, los medios que utilice deben facilitar las interacciones sociales para favorecer el aprendizaje, independiente de los medios usados para hacerlo. 


\section{Visión sistémica en la administración de la educación a distancia.}

La institución educativa a distancia se caracteriza por ser multicultural, al permitir el ingreso de individuos de diferentes regiones, culturas y naciones, distribuida mediante la red tecnológica que emplee, de perspectiva transnacional, al eliminar fronteras geográficas e intelectuales y un alto grado de coordinación dentro de toda su organización. Esto da más razón a la institucionalidad que debe tener esta modalidad educativa (Capacho, 2011). Para su diseño y desarrollo la concepción sistémica es el referente más adecuado.

Un sistema es un grupo de componentes interrelacionados que trabajan juntos hacia un fin común. Un sistema es, pues, más que la simple suma de sus partes. En educación a distancia, una estructura sistémica debe buscar siempre una relación entre sus partes: el docente, el estudiante, el contenido, el método, el medio ambiente, el material, la tecnología y el proceso de evaluación (Simonson, Smaldino, Albright \& Zvacek, 2009).

Para Sisk (como se citó en Graf, Albright \& Chacón, 2011), administrar es la coordinación de todos los recursos a través de los procesos de planificación, organización, dirección y auditoría con el fin de obtener objetivos preestablecidos. Recreando el concepto de administración al campo de la educación a distancia, puede considerarse como un proceso que permite alcanzar metas en una organización que oferte servicios y productos satisfaciendo la demanda en aprendizaje en línea. La educación a distancia como innovación educativa requiere hoy día de una administración de la tecnología de forma eficiente y pertinente que active la productividad y calidad.

Graf, et al. (2011), expresan las siguientes funciones centrales de una administración: planificar para establecer metas, planes y procedimientos; organizar el proceso de asignación de tareas y ejecución de las mismas; seleccionar y ubicar al personal en los cargos apropiados acorde a sus competencias; influenciar o guiar las actividades en la dirección apropiada para la maximización de la productividad, y auditar para medir el rendimiento de la organización. Las anteriores funciones son pertinentes para el contexto la educación a distancia que como un sistema complejo e integrado involucra a personas, procedimientos, ideas y dispositivos de una organización (AECT, 2004).

En el marco de un sistema de educación a distancia se presentan los siguientes subsistemas que desde su estructura sistémica permiten establecer una interrelación entre ellos: el regulatorio, el de los cursos, el de los estudiantes, el logístico y el de tecnología, propuestos por Graf, et al. (2011), los cuales pueden variar significativamente, de acuerdo con el ambiente específico y su alcance, Figura 5. 


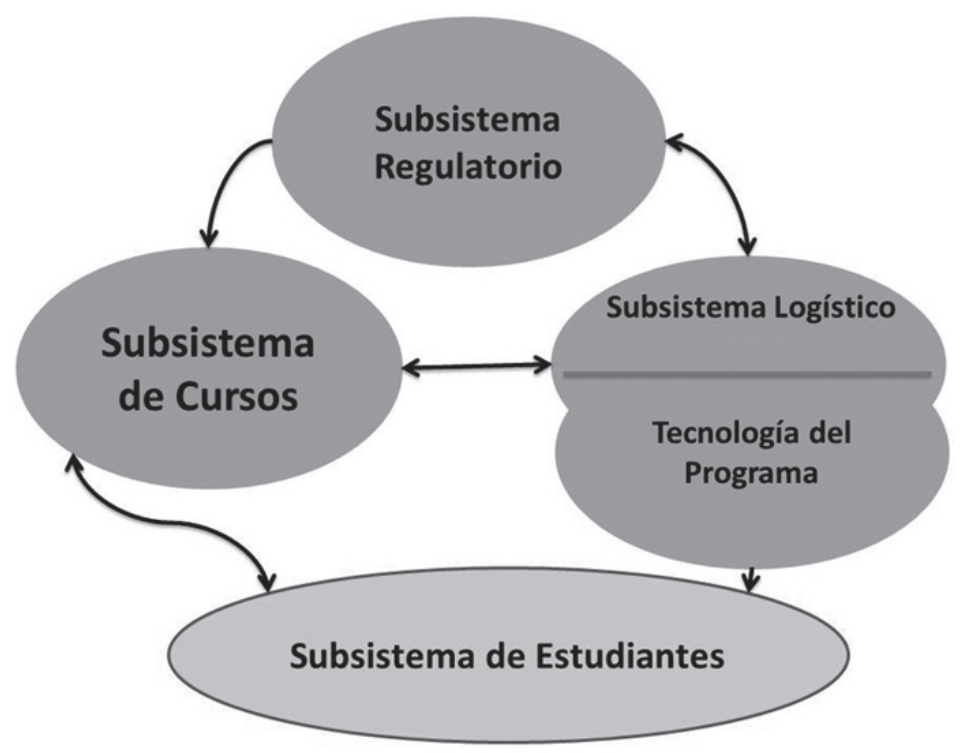

Figura 5. Subsistemas de la educación a distancia. Fuente: Chacón (2011).

Subsistema regulatorio. Para Graf et al. (2011), en el subsistema regulatorio se incluyen funciones tales como la administración del programa de formación, la toma de decisiones, la planificación, el financiamiento y la evaluación.

Algunas de las funciones regulatorias del administrador de educación a distancia pueden ser las siguientes:

1) Definir el grupo específico del público objetivo

2) Desarrollo de los programas, su planificación y promoción

3) Acreditación de los programas

4) La planificación estratégica

5) La responsabilidad por todos los aspectos financieros de los programas

6) La evaluación de los programas

7) El cumplimiento de los estándares

8) El cumplimiento de las regulaciones.

Subsistema de cursos de la educación a distancia. Para Sandia y Jonás (s.f.), la selección de una o varias tecnologías específicas de telecomunicaciones para ser utilizadas en la educación a distancia está determinada por varios factores. Entre ellos se pueden mencionar: los alcances y objetivos del programa, costos iniciales, personal necesario, características de los estudiantes, nivel de interactividad requerido, infraestructura tecnológica existente y compatibilidad 
de los equipos. Es por ello que los cursos de educación a distancia deben ser planificados y diseñados cuidadosamente, en todos estos aspectos, para garantizar su efectividad.

El diseño y desarrollo para los cursos a distancia estuvo basado en el estándar Instructional System Design (ISD), ampliamente utilizado a nivel mundial para el mejoramiento de la estructura de materiales, métodos y evaluación. Por tanto, el principio fundamental del ISD es que todos los aspectos del proceso enseñanzaaprendizaje deben ser definidos tomando en cuenta el comportamiento del estudiante, de tal forma que lo que se espera sea aprendido por el estudiante, pueda ser observado y medido (Moore, como se citó en Sandia y Montilva, s.f.).

Esta metodología sigue un modelo cíclico, continuo, en el que la idea central es que el desarrollo de la instrucción pueda ser dividida en cinco fases diferentes todas ellas interrelacionadas y en muchos casos solapadas. En la Figura 6, se observan las cinco etapas o fases importantes del modelo establecido por el ISD:

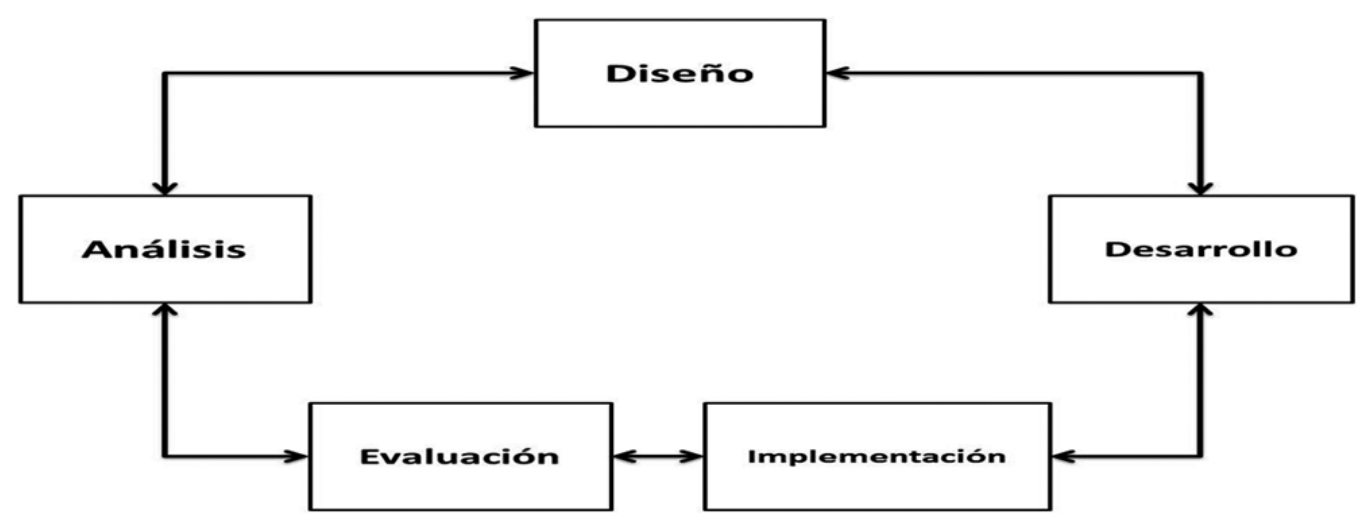

Figura 6. Etapas del modelo de ISD

1) Análisis. En esta primera fase se identifican las habilidades específicas involucradas en la conducción de un curso, así como las características de los estudiantes y del ambiente de enseñanza-aprendizaje. También se deben identificar cuáles son las necesidades de los estudiantes a fin de ejecutar las destrezas deseadas, en el nivel deseado.

2) Diseño. Las metas y objetivos del programa deben ser expresados en términos muy específicos, así como la estructura y forma del curso. En esta etapa deben ser seleccionados los medios de transmisión tomando en cuenta, entre otros factores, el costo inicial del medio, el personal disponible, las características del usuario, el nivel de interactividad deseado, la tecnología existente y la compatibilidad de equipos, para garantizar que el mismo sea efectivo. 
3) Desarrollo. En esta etapa se producen y prueban los materiales (videos, guías de estudio, teleconferencias, videoconferencia, Objetos Virtuales de Aprendizaje (OVA), etc.). Se da además, capacitación a los docentes y estudiantes en el uso de estos materiales.

4) Implementación. Es la etapa en la que los estudiantes se inscriben, los materiales son entregados o transmitidos por los canales de comunicación, y los estudiantes y el docente interactúan.

5) Evaluación. Etapa en la que se evalúa el proceso de aprendizaje, se califica a los estudiantes y se evalúa la efectividad del curso y los materiales ó medios utilizados.

En la educación a distancia, la información y actividades que deben realizarse durante el curso deben ser muy específicas y claras. El estudiante necesita tener en sus manos una estructura del contenido de la materia y del proceso de aprendizaje. Para esto, es necesario diseñar, para cada curso, una guía de estudio que además de presentar los objetivos a alcanzar, contenga una serie de indicaciones que deben seguir los estudiantes para el efectivo estudio del curso. Debe especificar las actividades, tareas, evaluaciones, así como el tipo de interacción entre estudiante-estudiante, estudiante-contenido, estudiantedocente y estudiante-interfase a ejecutarse durante el curso (Moore \& Kearsley, 1996).

Requerimientos del personal. Para este subsistema, es importante presentar la propuesta de conformación del equipo en el diseño de cursos:

1. Expertos en contenidos para el diseño de cursos bajo la modalidad e-learning.

2. Especialistas en el diseño material pedagógico, acorde a las necesidades de aprendizaje del estudiante bajo esta modalidad.

3. Docentes con formación de postgrado en diseño instruccional y educación a distancia.

4. Docentes con capacidad crítica, creativa, con altos niveles eficiencia, eficacia, efectividad, productividad, autónomos, con disciplina académica, con autocontrol, con manejo de las interacciones formativas, de trabajo colaborativo y de manejo de estrategias metodológicas, pedagógicas, didácticas y evaluativas, lo que invita a proponer grandes retos para satisfacer las necesidades de formación.

En las responsabilidades de las personas que conforman el subsistema de los cursos pueden incluir algunas de las que a continuación se nombran:

1. El aporte de desarrollo instruccional, de desarrollo profesional de los docentes, y de producción de medios digitales para proporcionar apoyo a 
los docentes en el desarrollo de los cursos en línea

2. En un sistema basado en la Internet, la autorización, la operación y el mantenimiento del sistema de administración de cursos.

3. La operación de un mostrador de ayuda las 24 horas del día, los 7 días de la semana, para apoyar a docentes y estudiantes

4. Asegurar que todo el software educativo cumple con los estándares de accesibilidad.

5. La evaluación y seguimiento de cada curso.

Subsistema de estudiantes. En el subsistema de los estudiantes, Kaye (1981) citado por Graf et al. (2011) lo describe como los procesos de admisión y de administración y control de su progreso. Se han determinado algunos procesos que favorecen su aprendizaje y corresponden a:

1. Definición de los perfiles de ingreso/egreso, admisión y matricula de los estudiantes.

2. Apoyo y orientación al estudiante, metodología de enseñanza y evaluación de los aprendizajes.

3. Prácticas externas y movilidad de los estudiantes.

4. Orientación profesional de los estudiantes.

5. Sistema de preguntas, quejas, reclamaciones y sugerencias.

Una parte de la responsabilidad del administrador de educación a distancia, es ayudar a garantizar que los estudiantes que se sientan atraídos por los programas de esta modalidad educativa, posean la preparación necesaria para tener éxito en los mismos. Las características típicas del estudiante exitoso deberían ser comunicadas por la institución educativa, como parte de su paquete de reclutamiento de estudiantes.

Subsistema logístico. En el subsistema logístico, Kaye (1981), citado por Graf et al. (2011), describe dos funciones principales del subsistema logístico: comprar y darle mantenimiento a los equipos, y la contratación y entrenamiento del personal.

En un sistema de educación a distancia basado en Internet, toda la infraestructura de la red entraría dentro del subsistema logístico. Esto incluye aspectos tales como servidores, routers, servidores de respaldo en caso de fallas en el servidor, generadores de emergencia durante apagones, un sistema de respaldo de archivos, y de almacenamiento externo, el propio acceso a Internet de la organización, y hasta las computadoras y estaciones de trabajo para el personal de apoyo técnico.

Este subsistema comprende la administración de la contratación de los recursos humanos: administrativos, docentes y personal de apoyo como profesionales expertos en el diseño y producción de medios digitales. Es por ello que se hace 
importante que los docentes que se contraten para hacer presencia docente en un entorno de educación a distancia, demuestre un nivel apropiado de preparación en este tipo de cursos (Brown, 1998), y tener un perfil competencias (Campos, Brenes \& Solano, 2010), clasifican las competencias de los docentes, en las que se especifican cada una de los conjuntos de competencias. Este perfil propuesto ha sido elaborado a partir del análisis de otras propuestas encontradas en la revisión de literatura que unido con los planteamientos anteriores se cristaliza en las siguientes competencias:

1. Competencias tecnológicas asociadas con el proceso educativo. Referido al dominio de las herramientas tecnológicas para potenciar procesos educativos, las cuales deben propiciar en los docentes algo más allá del uso de la herramienta como instrumento y trascendiendo la labor y competencia docente hacia el pensamiento digital, utilizando los recursos que ofrece la web 2.0. El docente debe dominar perfectamente los equipos informáticos y la plataforma en la que se desarrolle el curso, ya que su ingreso al curso requiere ciertos pasos que según (Caballero, 2005), debe mostrar lo siguiente:

-Dominio básico de herramientas tecnológicas orientadas a procesos educativos.

-Dominio básico de herramientas tecnológicas que permiten la comunicación para apoyar procesos de aprendizaje.

-Versatilidad para adoptar los cambios tecnológicos y adecuarlos a las necesidades de su contexto educativo.

-Diseño de materiales didácticos para apoyar el proceso de aprendizaje utilizando tecnologías.

2. Competencias investigativas. Las cuales debe propiciar constantemente reflexión sobre su práctica docente, hacia la búsqueda sistemática de respuestas que redunden en la mejora y transformación del proceso educativo que orienta. Sistematizar las prácticas puede ser una valiosa fuente de conocimiento. Estas competencias investigativas deben dinamizarse en el marco del saber colectivo, como menciona Unda donde confluya un arco iris de experiencias que dialoguen por sí mismas y que a su vez propicien coordinación entre ellas... "para sacar de la soledad al maestro innovador" (2002, p. 4).

3. Competencias pedagógicas y didácticas. Campo, Brenes y Solano (2010), mencionan que este tipo de competencias implican conocer y dominar propuestas pedagógicas efectivas, innovadoras, que propicien el aprendizaje significativo, autónomo y colaborativo. Capacidad para favorecer el desarrollo de procesos de autorregulación y metacognición en el estudiantado. Para ello, el docente debe mantenerse actualizado sobre los avances en el campo de la educación. Igualmente deben dominar los aprendizajes propios de esta modalidad, sus aciertos, sus retos y el abanico de los nuevos paradigmas desde estructuras de pensamiento complejo que las circunscriben. 
4. Competencias de liderazgo académico. Campo et al., (2010), mencionan que estas competencias "encierran saberes, actitudes y prácticas orientadas hacia la búsqueda permanente de la excelencia académica de sí mismo, del estudiantado y de la organización" (p.10).

5. Competencias cognitivas. Que afiancen su dominio disciplinar al servicio del acompañamiento en el proceso de aprendizaje. Debe responder a lo que tiene que saber y ser capaces de hacer el docente (OCDE, 2004). Además de posibilitar el diálogo con otras disciplinas para construir conocimiento desde otras orillas epistemológicas.

6. Competencias sociales que posibiliten la interacción. Comprende el conjunto de dominios cognitivos, socio afectivos, que favorecen la convivencia armoniosa y del desarrollo integral constante. Esto implica:

-Capacidad para desarrollar trabajo colaborativo en equipos interdisciplinarios.

-Desarrollar empatía con el estudiantado y demás colaboradores.

-Propiciar procesos de comunicación asertiva entre los actores educativos.

-Anticipar potenciales situaciones conflictivas en el entorno de aprendizaje e intervenir oportunamente en su atención.

-Desarrollar sentido de pertenencia con la organización.

-Manifestar respeto por la diversidad de los actores educativos para propiciar ambientes de aprendizaje armoniosos.

-Asumir responsablemente, el respeto a la propiedad intelectual de todas personas físicas y jurídicas.

-Promover en sus estudiantes y colaboradores la adopción del aprendizaje a lo largo de la vida como necesidad vital.

-Favorecer el desarrollo de comunidades de aprendizaje.

7. Subsistema de tecnología. Para Sandia y Montilva (s.f.), el subsistema tecnológico proporciona, opera y mantiene toda la infraestructura de equipos y sistemas necesarios para el subsistema anterior y para garantizar la comunicación interactiva entre otros subsistemas y debe proporcionar un entorno tecnológico de vanguardia, con servicios innovadores, de calidad y estables, contribuyendo y añadiendo valor a las actividades educativas de investigación y de gestión de la Universidad.

Para ello debe considerarse varios equipos de trabajo: un equipo que se encargue de gestionar los requerimientos docentes en el campo de la tecnología educativa y de gestión, un equipo de desarrollo y mantenimiento que gestione la calidad del desarrollo y el servicio de mantenimiento de las aplicaciones, un equipo de integración que realiza el diseño tecnológico y la verificación de la integración y la calidad de las aplicaciones, un equipo de operaciones que se encarga de 
gestionar las infraestructuras y el centro de datos para producir los servicios, y finalmente, un equipo de ayuda al usuario que gestiona la ventana única de atención a los usuarios y proporciona indicadores de calidad.

\section{Políticas para la educación a distancia}

Al ser la educación un servicio público, es deber del Estado establecer normas, principios y procedimientos para su regulación. Así es posible mantener la institucionalidad de los programas de formación formal y no formal de cara a la educación para toda la vida.

Se entiende como política las afirmaciones que establecen una norma, procedimiento o regla que facilitan las acciones institucionales en educación a distancia al asignar funciones y responsabilidades. Con ellas se busca el desarrollo, la eficiencia, la eficacia y la innovación en cada una de las etapas del proceso formativo institucional.

La regulación institucional comienza con el establecimiento de la normatividad externa, generalmente establecidas desde la Carta Magna, leyes y decretos que ordenan el servicio educativo desde su planeación, oferta, servicio y evaluación. Desde esa perspectiva, basados en la autonomía cada institución educativa regulará sus asuntos internos relacionados con la creación de programas, estructuras curriculares, proyecto educativo, docencia, investigación, evaluación, proyección social e impacto (Simonson, et al., 2009).

Estos autores establecen como áreas de desarrollo de política interna: Académicas, es decir, las relacionadas con la ontología del proceso de enseñanza-aprendizajeevaluación, currículo, movilidad académica en términos de ingreso, promoción, transferencia, estándares curriculares, evaluación académica, derechos y deberes de profesores y estudiantes, calendario académico entre otros. Finanzas, relacionada con costos del servicio, proyectos de inversión y demás. Cobertura geográfica e institucional mediante convenios, intercambios. Gobernabilidad, relacionada con representatividad, estructura de gestión, rendición de cuentas. Gestión laboral, mediante regulaciones estatutarias de estamentos dentro de la organización. Entorno legal, es decir, las regulaciones con Estado, comunidades y otras instituciones educativas. Apoyo al estudiante, referido a normas, servicios, formación para la modalidad educativa ofertada, apoyo académico, financiero y personal, entre otros. Técnicas, relacionadas con los recursos requeridos para el desarrollo del proceso de enseñanza - aprendizaje dentro de los programas, su administración y valoración y finalmente las Filosóficas, relacionadas con la concepción institucional de la modalidad, visión, misión, valores organizacionales entre otros (Simonson, 2007). 
En primera instancia, la normatividad externa se refiere a las condiciones que debe preparar el Estado para favorecer el desarrollo de la modalidad educativa a distancia. Si bien es cierto que al hacer parte del sistema educativo, se deba acoger a las condiciones de creación, diseño de programas, el ingreso de aspirantes y de profesores, los procesos de certificación para licencias de oferta y de acreditación de calidad, es necesario reglamentar condiciones específicas como es la de considerarla como modalidad educativa, más que una metodología en razón a la innovación de recursos, procedimientos y métodos específicos en la forma de promover el proceso de enseñanza-aprendizaje, la disponibilidad de conectividad en toda el área geográfica del país, la facilitación de tecnología para las regiones más necesitadas de educación, la alfabetización digital. Esta es una condición necesaria que el Estado debe garantizar para incorporar en igualdad de condiciones a todos sus ciudadanos a los beneficios de la educación y el bienestar.

Por lo tanto, las políticas de formación del talento humano implican procesos de alfabetización digital, algo que el Estado debe promover para desarrollar ampliamente las competencias requeridas para el uso pleno de las TIC, así será posible promover el aprender a aprender para toda la vida, además de promover la construcción colectiva de saberes para la solución específica de problemas locales, nacionales y en la participación internacional generada desde la sociedad del conocimiento (Graterol y Useche, 2004; Blásquez y Alonso, 2005; Arévalo, 2005).

Finalmente, el desarrollo de la modalidad de educación a distancia requiere del apoyo del Estado con el fin de generar las condiciones adecuadas que permitan el uso de los medios para mediar el acto de enseñanza y aprendizaje, establecer condiciones de igualdad con otras modalidades o metodologías educativas más tradicionales y promover la ventaja estratégica de la educación para toda la vida usando los medios. A las instituciones de educación a distancia, vincularse para promover programas de alta calidad, entregar egresados competentes y compartir los recursos para el desarrollo del currículo, estrategias de enseñanza, estrategias de aprendizaje, modos diferenciados de evaluación y certificación de desempeño de estudiantes y profesores, como una acción programática para brindar nuevas formas de educación acordes a las necesidades culturales, sociales y cognitivas de los colombianos que desean ayudar en el desarrollo de la Nación.

\section{La calidad en educación a distancia}

En la búsqueda de una educación de calidad las IES y los programas a distancia deben ser objeto de análisis y reflexiones permanentes desde el paradigma de la investigación educativa en tanto que este se convierte en una fuente de conocimientos para mejorar la calidad, la eficacia, la eficiencia y el impacto, 
para este caso, de los programas de educación a distancia; los resultados que se obtengan darán cuenta de los niveles de eficiencia o deficiencia de los programas como también de las metodologías para reformular programas (ICFES, 1996). Como todo mejoramiento implica una acción de cambio Weiss (1999), plantea que la evaluación de programas se vincula a la toma de decisiones en cuanto a si se da continuidad o no al programa, mejorar los procesos, incorporar o no alguna de sus partes, ampliar la oferta, redistribución de recursos y aceptar o rechazar algún enfoque o teoría que sustenta el programa.

Para impartir una educación de calidad, las Instituciones de Educación Superior (IES) deben orientar su actividad a satisfacer una necesidad específica, las expectativas de los estudiantes, de otras organizaciones, del Estado, cumplir con la normatividad del país o países donde se encuentre ofertando sus servicios, el aporte al bien común, a brindar oportunidades para todos y que sus costos sean adecuados (Derrico, 2004). Así a la organización educativa le conviene incorporar a su cultura políticas, procedimientos, instrumentos de evaluación y de análisis de resultados que le permitan justificar la inversión, logros de metas, mejorar objetivos y procedimientos para la toma de decisiones de continuar, expandir o eliminar programas (Thompson, \& Irele, 2007).

La educación a distancia en Iberoamérica y en Colombia desempeña un papel fundamental al permitir mayor acceso a la educación, especialmente a personas que no han podido ingresar al sistema educativo por razones sociales, económicas y geográficas entre otras (Lupion \& Rama, 2010). En el caso de Colombia al 2008 contaba con 137 universidades privadas y 73 públicas (Didriksson, 2008), para el 2006 se tenían 562 programas a distancia y al 2010 se tienen 1236 indicando un crecimiento significativo y 199 programas virtuales (El Observatorio de la Universidad Colombiana, s.f.), mostrando que esta modalidad está tomando fuerza al tener cierta credibilidad entre la población de aspirantes a la educación superior (MEN, 2009). Sin embargo frente a este crecimiento cuantitativo la cuestión central para las IES es apostarle a la calidad de los programas ofertados, lo que implica una amplia reflexión y una profunda evaluación; de allí que se hace necesario establecer criterios como filtros para contrastar que las propuestas educativas son confiables y de calidad en la práctica (Fainholc, 2004). Esta misma autora afirma que no puede hablarse en términos absolutos de calidad y que por ello las IES deben considerar diversos referentes contextualizados para proceder a su análisis y evaluación.

En este sentido Sarramona (2001), recomienda que los programas en la educación a distancia deben posibilitar al estudiante aprender de acuerdo con sus decisiones personales de lugar, momento, ritmo, nivel de profundización, entre otros; y la calidad se asegura cuando hay una planificación rigurosa, materiales didácticos que contengan la totalidad de los contenidos y las instrucciones precisas, garantizar la adaptabilidad frente a las diferencias personales de los estudiantes, posibilidades de comunicación permanente entre profesor y 
estudiante, procesos de autoevaluación y heteroevaluación del estudiante, del docente y de la institución.

Tabla 2. Consideraciones a tener en cuenta en la evaluación de un programa a distancia

\begin{tabular}{|c|c|}
\hline $\begin{array}{c}\text { Consistencia del programa } \\
\text { con la misión institucional }\end{array}$ & $\begin{array}{c}\text { Los evaluadores deben buscar evidencias } \\
\text { que demuestren que la educación a } \\
\text { distancia ofrecida esté en coherencia con } \\
\text { la misión institucional y tenga personal de } \\
\text { apoyo y presupuesto adecuado. }\end{array}$ \\
\hline $\begin{array}{c}\text { Disposiciones para la } \\
\text { supervisión del programa y la } \\
\text { rendición de cuentas }\end{array}$ & $\begin{array}{c}\text { Los procesos de supervisión y control de } \\
\text { los asuntos académicos y técnicos deben } \\
\text { ser completamente transparentes a los } \\
\text { evaluadores. }\end{array}$ \\
\hline $\begin{array}{c}\text { Prestación de servicios de } \\
\text { apoyo a los estudiantes }\end{array}$ & $\begin{array}{c}\text { Los evaluadores pueden revisar los sitios } \\
\text { web y demás medios que la institución } \\
\text { provea a los estudiantes para asegurar } \\
\text { su acceso a los contextos de aprendizaje } \\
\text { específicamente diseñados para esa función. }\end{array}$ \\
\hline $\begin{array}{c}\text { Disponibilidad de un } \\
\text { sistema de evaluación y de } \\
\text { instrumentos de medición }\end{array}$ & $\begin{array}{c}\text { La evaluación es un componente crítico de } \\
\text { un programa de educación a distancia, por } \\
\text { lo que debe incorporarse desde la fase de } \\
\text { planeación del programa. }\end{array}$ \\
\hline
\end{tabular}

Tomado de Kelsey, Lindner \& Dooley, 2005, p. 872.

Desde una estructura lógica Cosphere (2004), propone otros aspectos a considerar al momento de valorar la calidad en la educación a distancia. Señala que independiente de la modalidad en que se ofrezca un programa educativo a distancia mínimamente debe tener clara su fundamentación y función, un modelo pedagógico, un modelo tecnológico, un modelo operativo, la estructura de la organización y las estrategias para la implementación del programa. Para Nuñez (s.f.), la calidad de la educación a distancia estará dada en la medida que las instituciones desarrollen una política que fomente la educación a distancia, se definan políticas relacionadas con la docencia, investigación e innovación, se diseñe e implemente un plan para la infraestructura tecnológica, y se oferten cursos que cumplan al menos con los estándares mínimos de calidad para el diseño, desarrollo y oferta de los mismos.

Por otra parte Lindsay (1982), plantea que para definir la calidad en esta modalidad deben considerarse los factores económicos, pedagógicos y los administrativo y de gestión. En lo económico recomienda examinar la productividad de la educación como formación de capital y recursos humanos. Desde lo administrativo y de gestión ha de verificarse como la organización de recursos se movilizan para ofrecer los servicios de educación e investigación y de extensión universitaria. Y en lo pedagógico recomienda valorar la coherencia de profesores, instrucción, tiempo y recursos de enseñanza, frente a los resultados educativos. 
Desde Kelsey, Lindner, y Dooley (2005), la evaluación como componente de la cultura de calidad de los servicios educativos de una institución de educación a distancia, requiere establecer principios que le permita tener evidencias de los aspectos definidos en la Tabla 2.

La cultura de la calidad debe tener unos fundamentos filosóficos, ontológicos y prácticos muy claros para la organización. La misión, la visión institucional y las metas determinan el norte de la organización, los manuales de calidad, los procedimientos e instrumentos de recuperación de información y de análisis de resultados deben ser conocidos y manejados ampliamente no solo por los miembros de la organización sino por los evaluadores externos como garantía de transparencia, de eficiencia y eficacia de la organización hacia la sociedad a la que sirve (Kelsey, Lindner, \& Dooley, 2005). Incluso pueden ser elementos de contacto entre diferentes organizaciones educativas que quieren compartir recursos y facilitar la movilidad de estudiantes y de docentes (Cartelli, Stansfield, Connolly, Jimoyiannis, Magalhães, \& Maillet, 2008).

\section{Referencias bibliográficas}

Aliste, F. 2006. Modelo de comunicación para la educación a distancia. Análisis experimental de una plataforma de e-learning. Tesis doctoral. Barcelona: Universidad Autónoma de Barcelona. Recuperado de: http://www.tdx.cat/bitstream/ handle/10803/4126/caf1de2.pdf;jsessionid=A91674B4258EB192FoC61E4FD7E26A47. tdx2? sequence $=1$

Anderson, T. Kuskis, A. 2007. Modes of interaction. En: Moore, M. G. (Ed.). Handbook of distance education. (295-309) (2 $2^{\mathrm{a}}$. Ed.) Mahwah, N.J: Lawrence Erlbaum Associates, Publishers.

Ángeles, S. 2013. Experiencias y tendencias de la educación abierta en universidades españolas: La UNED abierta. Open Education Week, Marzo 11 a 15 de 2013. Recuperado de: http://www.google.com.co/url?sa=t\&rct=j\&q=\&esrc=s\&source=web\&cd=1\&ved= oCCwQFjAA\&url=http\%3A\%2F\%2Fe-archivo.uc3m.es $\% 2$ Fbitstream $\% 2 \mathrm{~F} 10016 \% 2 \mathrm{~F} 16532 \% 2$ F1\%2Fexperiencias_sanchez-elvira_OEW_2013.pdf\&ei=XEWSUdjGGqmQoQHJ3IDACW \&usg=AFQjCNEJ4ZHcXg-AbPyt5zc4blZpnWU_bg\&bvm=bv.46471029,d.dmQ

Anónimo. s.f. Aprender a aprender. Recuperado de: http://tochtli.fisica.uson.mx/ educacion/aprender_a_aprender/Aprender\%20a\%20aprender.pdf 
Arancibia, H. Pérez S. 2002. Antecedentes conceptuales, tecnológicos y pedagógicos para la propuesta de un modelo educativo a distancia. Estudios Pedagógicos (28) 157164. Recuperado de: http://mingaonline.uach.cl/pdf/estped/n28/arto9.pdf

Area, M. 2002 ¿Qué aporta internet al cambio pedagógico en la educación superior? En: Pérez, R. (Coord) Redes multimedia y diseños virtuales. Oviedo: Actas del III Congreso Internacional de Comunicación, Tecnología y Educación. Recuperado de: http:// tecnologiaedu.us.es/nweb/htm/pdf/tres.pdf

Arévalo, Z. 2005. Necesidad de políticas de educación en medios. Comunicar, 25, 53-58. Recuperado de: http://rabida.uhu.es/dspace/bitstream/handle/10272/1216/b15242638. pdf?sequence $=1$

Association for Educational Communications and Technology AECT. 2004. The definition of educational technology. Recuperado de: http://www.indiana. edu/ molpage/Definition\%200f\%20ET_classS05.pdf

Barberá, E. 2008. Aprender e-learning. Barcelona: editorial Paidós.

Berners-Lee, T. Hendler, J. Lasila, O. 2001. The semantic web. Scientific American 284. Recuperado de http://www.scientificamerican.com/article.cfm?id=the-semantic-web

Blázquez, F. Alonso, D. 2005. Apuntes para la formación del docente de e-learning. Enseñanza \& teaching. Revista interuniversitaria de didáctica 23, 65-86. Recuperado de http://e-spacio.uned.es/fez/eserv.php?pid=bibliuned:20222\&dsID=apuntes formacion.pdf

Cabero, J. 2006. Bases pedagógicas del e-learning. Revista de Universidad y Sociedad del Conocimiento. 3(1). Recuperado de http://www.uoc.edu/rusc/3/1/dt/esp/cabero. html

Capacho, P. 2011. Evaluación del aprendizaje en espacios virtuales: TIC. Barranquilla, Colombia: Editorial Universidad del Norte, Grupo Editorial Ibañez.

Cartelli, A. Stansfield, M. Connolly, T. Jimoyiannis, A. Magalhães, H. Maillet, K. 2008. Towards the development of a new model for best practice and knowledge construction in virtual campuses. Journal of Information Technology Education. num7, 120-134.

Citelli, A. 2011. Ensino a distancia na perspectiva dos diálogos com a comunicação. Comunicação. Mídia e Consumo, 8(22), 187-209.

Comisión Económica para América Latina y el Caribe (CEPAL) 2001. Objetivos de desarrollo del milenio: una mirada desde América Latina y el Caribe en: la educación como eje del desarrollo humano. Recuperado de http://www.eclac.org/publicaciones/ $\mathrm{xml} / 1 / 21541 /$ capitulo3.pdf 
Pedro Antonio Vela González, Vicky del Rosario Ahumada de la Rosa, José Humberto Guerrero Rodríguez Conceptos estructurantes de la educación a distancia. Artículo de revisión.

Cosphere Consulting Group- 2004. Modelo de Educación a Distancia. Documento interno de la Coordinación de Educación Tecnológica y a Distancia. México. ITSON.

Derrico, E. 2004. La organización y administración de centros educativos: Una visión desde el concepto de las buenas prácticas en educación. Tecnología y Comunicación Educativas. (40), 22-36. Recuperado de: http://investigacion.ilce.edu.mx/tyce/40/art3. pdf

Díaz, B. Hernández, R. 2010. Estrategias docentes para un aprendizaje significativo. Una interpretación constructivista. (3 ${ }^{\mathrm{a}}$. Ed.). México: McGraw Hill.

Díaz, V. 2011. Análisis de la modalidad educativa del sistema educativo de la ley orgánica de educación 2009: ¿Un desafio a la educación especial? Provincia, (26), 145-158. Recuperado de: http://www.google.com.co/url?sa=t\&rct=j\&q=\&esrc=s\&source=we b\&cd $=1 \&$ ved $=0 C$ CwQFjAA\&url=http $\% 3 A \% 2 F \% 2 F w w w$. saber.ula.ve $\% 2$ Fhandle $\% 2 F 12345$ 6789\%2F36151\&ei=6bKSUfiqMPW24AOokoGQDg\&usg=AFQjCNHE6P4XAjDVKLeiFfGj rmlfvjAdhA\&bvm=bv.46471029,d.dmg

Didriksson, A. 2008. Contexto Global y Regional de la Educación Superior en América Latina y el Caribe. En: Gazzola, A. L. \& Didriksson, A. (Ed.). Tendencias de la Educación Superior en América Latina y el Caribe. Bogotá.: IESALC-UNESCO. Recuperado de: http://www.iesalc.unesco.org.ve/index.php?option=com_content\&view=article\&id= 2\&ltemid=408\&lang=es.

El Observatorio de la Universidad Colombiana. (s.f.). Distribución, Según la Modalidad en la que se Aprende, de los Programas de Educación Superior. Recuperado de: http:// www.universidad.edu.co/index.php?option=com_content\&task=view\&id=32\&ltem id $=99$.

Fainholc, B. 2004. La calidad en la educación a distancia continúa siendo un tema muy complejo. RED Revista de Educación a Distancia. (12). Recuperado de: http://revistas. um.es/red/article/view/25311/24591

Fandos, G. 2006. El reto del cambio educativo: Nuevos escenarios y modalidades de formación. Educar, 38, 243-258. Recuperado de: http://ddd.uab.cat/pub/ educar/0211819Xn38p243.pdf

García L. 2002. La educación a distancia. De la teoría a la práctica. México: Ariel educación.

Garrison, D. Anderson, T. 2005. El e-learning en el siglo XXI. Barcelona: Ediciones Octaedro, S. L.

Graf, D. Albright, M. Chacón, F. 2011. Administración y Evaluación de la Tecnología Instruccional y la Educación a Distancia. North Miami Beach, Fla.: Nova Southeastern University 
Graterol, M, Useche, M. 2004. Los factores politicos y académicos en la formación de los recursos humanos para la educación a distancia en la educación superior de las universidades de Venezuela. I Congreso Internacional sobre Tecnología Documental y del Conocimiento. Madrid. Recuperado de: http://eprints.rclis.org/5380/1/Madrid8.pdf

Herrera, B. 2005. Consideraciones para el diseño didáctico de ambientes virtuales de aprendizaje: Una propuesta basada en las funciones cognitivas del aprendizaje. Revista Iberoamericana de Educación (38), 1-20. Recuperado de: http://www.rieoei.org/ deloslectores/1326Herrera.pdf

Instituto Colombiano para el Fomento de la Educación Superior - ICFES. 1996. Investigación evaluativa. Recuperado de: http://contrasentido.net/wp-content/ uploads/2007/08/modulo6.pdf

Kaplun, M. 1998. Una pedagogía de la comunicación. Madrid: Ediciones de la Torre. Recuperado de: http://ebookbrowse.com/una-pedagogia-de-la-comunicacion-pormario-kaplun-pdf-d277467717

Kaufman, D. 1989. Third generation course design in distance education, en: Sweet, R. (Ed.), Postsecondary distance education in Canada. Policies, practices and priorities. Athabasca: Athabasca University Press/Canadian Society for Studies in Education. P. 51-73.

Kelsey, K. D., Lindner, J. R., \& Dooley, K. E. (2005). "Evaluating Online Programs". En: Howard, C., Boettcher, J., Justice, L., Schenk, K., Rogers, P., \& Berg. G. (Eds.), Encyclopedia of Distance Learning (p. 872). Copyrigth 2005 por Idea Group Inc.

Lindsay, A. 1982. Institucional performance in higher education: The efficiency dimension. Review of Educational Research, 52 (2), 175-199.

Lupion, T. Rama, C. (s.f.) Algunas de las Características Dominantes de la Educación a Distancia en América Latina y el Caribe. En: Lupion, T. P. \& Rama, C. (Coord.) La Educación Superior a Distancia en América Latina y el Caribe. Realidades y Tendencias. Brasil.: Universidad do Sul de Santa Catarina. Recuperado de: http://sitio.flacso.edu. uy/wpcontent/uploads/2009/12/Libro_EduDist2009.pdf.

Marcelo, C. 2001. Aprender a enseñar para la sociedad del conocimiento. Revista Complutense de Educación, 12(2), 531-539. Recuperado de: http://www.google.com. $\mathrm{co} /$ url? sa $=\mathrm{t} \& \mathrm{rct}=\mathrm{j} \& \mathrm{q}=\& \mathrm{esrc}=\mathrm{s} \&$ source $=$ web $\& \mathrm{~cd}=1 \& \mathrm{ved}=0 \mathrm{CC}$ WQFjAA\&url=http\%3A $\% 2$ F\%2Frevistas.ucm.es\%2Findex.php\%2FRCED\%2Farticle\%2Fdownload\%2FRCED010 1220531A\%2F16749\&ei=71qSUdDBBIW-4APh4IDwAQ\&usg=AFQjCNFn9OKIP6VRfhUg8IMfWL_-izitA\&bvm=bv.46471029,d.dmg

Martín, S. Verde, M. Yelicich, C. 2011. La enseñanza a distancia (EaD) en las carreras universitarias de bibliotecología en Argentina. II Jornadas sobre experiencias e investigación en educación a distancia y tecnología educativa. Argentina, 22 y 23 de agosto. Recuperado de: http://eprints.rclis.org/17459/1/2011\%20EaD\%20 bibliotecolog\%C3\%ADa.pdf 
Pedro Antonio Vela González, Vicky del Rosario Ahumada de la Rosa, José Humberto Guerrero Rodríguez Conceptos estructurantes de la educación a distancia. Artículo de revisión.

Ministerio de Educación Nacional, MEN. 2009. Educación Virtual o Educación en Linea. Recuperado de: http://www.mineducacion.gov.co/1621/article-196492.html

Moore, M. Kearsley, J. 1996. Distance Education. A System View. Belmont, CA: Wadsworth Publishing Company.

Moore, M. (1990). The effects of Distance Learning: A summary of the Literature. ACSDEÑ: Research Monograph, No. 2. University Park, PA: Pennsylvania State University.

Nuñez, M. (s.f.) Calidad y efectividad de la Educación a distancia. Recuperado de: http://www.uprm.edu/ideal/calidad.swf

Open Society Institute. 2007. Declaración de Ciudad del Cabo para la educación abierta. Recuperado de: http://openaccess.uoc.edu/webapps/o2/handle/10609/7182? mode=simple\&submit_simple=Muestra+el+registro+sencillo+del+documento

Perraton, H. 1981. A theory for distance education [Una teoría para educación a distancia]. Prospects: Quarterly Review of Education, 11(1), 13-24.

Ramos, M. Arias, M. 2012. Desafíos y riesgos de la educación a distancia en los nuevos contextos comunicacionales. SEDECI. Reservorio institucional de la UNLP. Recuperado de: http://sedici.unlp.edu.ar/bitstream/handle/10915/18537/Documento_completo. pdf?sequence $=1$

Rojas, R. 2003. La comunicación educativa en las condiciones de la educación a distancia. Revista Pedagogía Universitaria, 8 (3), 73-80.

Sandia, B. Jonás, J. (s.f.) Aspectos Metodológicos para el Desarrollo de Programas de Estudios Interactivos a Distancia Basados en WEB. Recuperado el 21 de octubre de 2011 de http://www.saber.ula.ve/bitstream/123456789/15844/1/04_aspectos_metodo.pdf

Sarramona, J. 2001. Evaluación de programas de educación a distancia. RIED-Revista Iberoamericana de Educación a Distancia. 4 (1). Recuperado el 9 de septiembre de 2011, de: http://www.utpl.edu.ec/ried/images/pdfs/vol4-1/evaluacion_programas.pdf

Schlosser, A. Simonson, M. 2010. Distance education. Definition and glossary of terms. (3a. Ed.). Charlote, NC.: Information Age Publishing.

Serrano, B. Muñoz, M. 2008. Complementariedad en las modalidades educativas: Presencial y a distancia. Revista de Educación a Distancia, VIII(20), 1-23. Recuperado de: http://www.redalyc.org/articulo.oa?id=54702003

Simonson, M. 2007. Institucional policies issues. En: Moore, M. G. (Ed.). Handbook of Distance Education. (355-362). (2a. Ed.). Mahwah, N.J.: Lawrence Erlbaum Associates, Publishers. 
Simonson, M. Smaldino, S. Albright, M. Zvacek, S. 2009. Teaching and learning at a distance education. (4a. Ed.). Boston, M.: Pearson.

Thompson, M. Irele, M. 2007. Evaluating distance education programs. En: Moore, G. M. (Ed.). Handbook of distance education. (419-436). (2a. Ed.). Mahwah, NJ.: Lawrence Erlbaum Associates, Publishers.

Turpo, G. 2012. La modalidad educativa blended learning en las universidades de Iberoamérica: Análisis y perspectivas de desarrollo. Educar, 48(1), 123-147. Recuperado de: http://www.google.com.co/url?sa=t\&rct=j\&q=\&esrc=s\&source=web\&cd=2\&ved= oCD8QFjAB\&url=http\%3A\%2F\%2Fwww.raco.cat\%2Findex.php\%2FEducar\%2Farticle $\% 2 \mathrm{~F}$ download\%2F252995\%2F339740\&ei=RqmSUfWjOfOw4AOYx4CgBw\&usg=AFQjCNFSJ sKedUDloxiCAQlq2_ixQ8POAg\&bvm=bv.46471029,d.dmg

Unesco. 2012. Declaración de París sobre los REA (Recursos Educativos Abiertos). Recuperado de: http://www.unesco.org/new/fileadmin/MULTIMEDIA/HQ/CI/CI/pdf/ Events/Spanish_Paris_OER_Declaration.pdf

Weiss, C. 1999. Investigación evaluativa. Ed. Trillas, México.

Wompner, F. Fernández, M. 2007. Aprender a aprender. Un método valioso para la educación superior. Observatorio de la Economía Latinoamericana, 72, 1-11. Recuperado de: http://mpra.ub.uni-muenchen.de/3613/1/MPRA_paper_3613.pdf 